\title{
Etnoscience Dan Etnotechnologi Preaching Di Moluccas
}

\author{
Syarifudin $^{\mathrm{a}, *}$ \\ ${ }^{a}$ Fakultas Ushuluddin dan Dakwah, IAIN Ambon, Indonesia \\ *Corresponding author: syarifiainambon99@gmail.com \\ Article history \\ Received: 10/10/2016 \\ Received in revised form:13/1/2017 \\ Accepted: 04/03/2017
}

\begin{abstract}
Penelitian ini berkaitan dengan studi etnoscience dan etnoteknology dakwah pada masyarakat adat di Negeri Tulehu Maluku Tengah Provinsi Maluku dalam mentransformasikan ajaran agama sebagai konsep hidup. Masalah penelitian ini memotret imbas teknologi moderen terhadap etnoscience dan etnoteknology dakwah di Desa Tulehu yang melahirkan prilaku bermasalah, adabtasi prilaku, dan adabtasi budaya. Penelitian ini menggunakan metode kualitatif. Masalah penelitian ini adalah bagaimana struktur terbentuknya etnoscience dan etnoteknology Dakwah dan bagaimana imbas teknologi moderen merubah watak bergama kaum adat di negeri Tulehu di Maluku. Teknik pengumpulan data menggunakan metode Focus Group Dicussion dan wawancara mendalam dengan tokoh adat, dan masyarakat. Etnoscience dan etnoteknology dapat mencegah peredaran limbah informasi negatif yang berpotensi mengganggu alam pikiran masyarakat. Tradisi etnoscience dan etnotechnology komunitas di Negeri Tulehu Provinsi Maluku Patawala (Memanggil Orang Keluarga); sistem penyebaran atau konstruksi sosial yang levelnya pada keluarga dengan menggunakan bahasa etnokomunikasi. Pasaware (penghormatan adat) biasanya dilakukan di masjid untuk hari-hari besar agama Islam. Tabaos Titah; Tabaos titah ini berfungsi sebagai media konstruksi sosial untuk publikasi pesan-pesan raja yang telah diputuskan dalam Baileo (rumah adat). Melalui etnoscience dan echnoteknology tradisi untuk menjaga, merawat, budaya etnokomunikasi sebagai tradisi katahanan sosial di Maluku. Kajian temukan tiga rumusan; 1). Adanya dominasi teknologi moderen dalam meraih simpati generasi muda dari aspek pembentukan karakter dan prilaku. 2). Kemudahan media sosial dalam transformasi budaya mengalami adabtasi sosial yang kurang terarah secara baik karena kontenya berorientasi pada bisnis semata. 3). Tradisi etnoscience dan etnoteknologi sebagai kekuatan budaya adalah model transformasi adat dan agama untuk penguatan daya imun masyarakat melalui etnoscience dan etnoteknologi sebagai metode transformasi pengetahuan yang humanis.
\end{abstract}

Keywords: etnoscience, etnoteknologi, dan dakwah.

\begin{abstract}
Abstrak
This research deals with the study and etnoteknology etnoscience propaganda on indigenous peoples in the State Tulehu Central Maluku Maluku province in transforming the religious teaching as a living concept. The research problem is photographing the impact of modern technology on etnoscience and etnoteknology propaganda in the village that gave birth Tulehu problematic behavior, adabtasi behavior, and adabtasi culture. This study uses a qualitative method. The research problem is how to structure formation and etnoteknology etnoscience Da'wah and how the impact of modern technology changed the nature of indigenous people in the country Bergama Tulehu in Maluku. The data collection technique using Focus Group dicussion and in-depth interviews with traditional leaders, and community. Etnoscience and etnoteknology can prevent waste circulation of negative information that potentially disturb the minds of the public. Etnoscience traditions and communities in the State etnotechnology Tulehu Patawala Maluku Province (Calling People Family); system deployment or social construction at the family level by using language etnokomunikasi. Pasaware (customary homage) is usually done in the mosque for holy days of Islam. Tabaos The statutes; Tabaos commandment serves as a medium for the publication of the social construction of the messages king was resolved in Baileo (traditional house). Through etnoscience and echnoteknology tradition to maintain, nurture, culture etnokomunikasi as social katahanan tradition in Maluku. Studies have found three formulas; 1 ). Their dominance of modern technology in young people gain the sympathy of the aspects of the formation of character and behavior. 2). Ease of social media in the cultural transformation experienced less social adabtasi directional well as kontenya purely business oriented. 3). Etnoscience and etnoteknologi tradition as a cultural force is customary and religious transformation model in order to strengthen the immune community through etnoscience and etnoteknologi as humane method of transformation of knowledge.
\end{abstract}

Kata Kunci: etnoscience, etnoteknologi, and preaching 


\subsection{PENDAHULUAN}

Sejak Maluku diterjang konflik yang dikenal dengan istila idul fitri berdarah atau tragedi krisis kemanusiaan antara basudara Salam-Sarane (Islam dan Kristen) maka wilayah Provinsi Maluku saat itu mengalami penderitaan yang sangat pedih. Setelah pasca konflik terjadi segregasi pemukiman penduduk. Muslim tinggal dikawasan pesisir dan kristen tinggal di pegunungan atau istila adatnya weluni (pegunungan) wemale (pesisir). Jumlah penduduk di lokasi penelitian kurang lebih 14.000 jiwa yang dulunya memiliki kekuatan etnoscience dan etnoteknologi dalam proses transformasi pengetahuan. Sejak tahun 2013 setelah produksi media komunikasi global berkembang pesat maka negeri adat ini mengalami suatu realitas baru yang dikenal dengan masyarakat transformatif. Cirinya mereka sedang mengalami perubahan sosial yang sangat kompleks akibat derasnya dominasi medio sosial dalam mengkonstruksi berita sementara daya kritis masyarakat masih sangat rendah untuk menelaah, memaknai, dan menjelaskan setiap watak dari sebuah informasi di media sosial.

\subsection{METODE}

Penelitian ini menggunakan metode kualitatif yang menjelaskan fenomena alamiah menjadi ilmiah proses perubahan etnoscience dan etnotechnology teknologi menggunakan studi fenomenologi, studi fenomenologi menggunakan kerangka konseptual. Terminology ini terfokus pada sistem informasi etnis tertentu dalam menggunakan perangkat pengetahuan etnoscience dan etnotechnology yang berbeda dengan etnis lain. Kajian ini memilih studi dakwah yang memotret pola etnoscience dan etnotechnology masyarakat di kota Ambon. Dalam proses pengumpulan data menggunakan teknik wawancara mendalam, Focus Group Discussion (FGD), dan dokumentasi.

\subsection{ETNOSCIENCE DAN ETNOTEKNOLOGI}

Makna leksikal dari istilah etnoscience berasal dari bahasa Yunani yang berarti "bangsa" dan scienti berasal dari bahasa latin yang bermakna pengetahuan. Berarti jika disebut etnoscience berarti pengetahuan bangsa/suku/etnis. Menurut Sturtevan (1961:99) dapat difahami bahawa etnoscience adalah pengetahuan yang dimiliki oleh suatu bangsa/ komunitas, etnis, suku kelompok sosial tertentu. Etnotechnology adalah instrument teknik yang dimiliki masyarakat atau komunitas etnis tertentu yang digunakan sebagai sarana penunjang untuk menyelesaikan persoalan dilingkungan tertentu demi memenuhi kebutuhan primer dan kebutuhan sekunder untuk mencapai tujuan tertentu yang diwariskan dari generasi ke generasi dalam kurun waktu tertentu (Warner and Feton, 1970: 573; Peter L. Berger dan Thomas Luckman (2013: 12).

Rajah 1: Kerangka proses berpikir dalam kajian etnoscience dan etnoteknologi

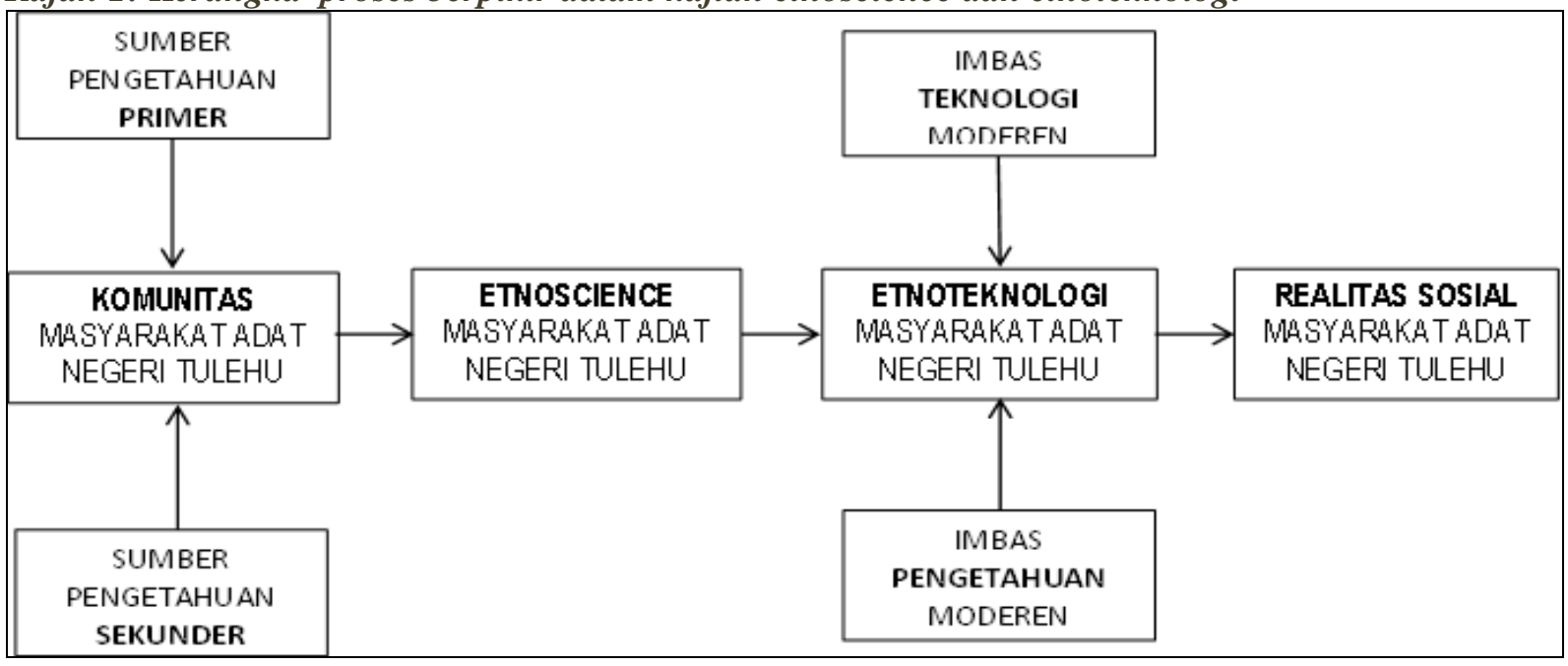


Dari pengertian ini sebagai pembatasan dari fokus kajian ini bahwa yang dimaksud etnoscience dan etnotechnologi dakwah adalah; produksi pengetahuan dan fasilitas teknologi yang digunakan etnis tertentu dalam berkomunikasi transenden sebagai kearifan dalam melakukan konstruksi komunikasi ritual di Desa Tulehu sebagai media komunikasi untuk melakukan interaksi sosial, penyebaran informasi, pemenuhan kebutuhan jasmani dan rohani yang dilakukan oleh etnis tertentu. Rajah 1 merupakan kerangka proses berpikir dalam kajian etnoscience dan etnoteknologi.

\subsection{Komunitas Masyarakat Adat Negeri Tulehu}

Peta sosial masyarakat negeri Tulehu sebagai gambaran untuk menjelaskan realitas sosial yang bergerak laksana mekanis itu digerakkan oleh beberapa faktor antara lain; pendidikan, kesehatan, dan etnotechnology adat yang disepakati dan diputuskan oleh negeri. Model peradaban Islam Maluku didesain oleh berbagai unsur budaya, seperti Arab, Eropa, India, dan Cina sehingga membentuk citra budaya yang sangat kompleks dengan paradigma dan perspektif masing-masing (Usman Thalib, 2012:3). Ekspresi kekayaan khazanah peradaban Islam Maluku dalam naskah kuno adalah penting bagi pengembangan akademik di Perguruan tinggi untuk mengetahui peristiwa keagamaan di masa lalu (Nor Huda, 2013: 403). Ketika kekayaan akademik ini tidak dijaga, dirawat, dan dilestarikan dengan baik. Peradaban Maluku juga dikenal dengan Seni Budaya Qasidah dan artikulasi religi melalui sajak-sajak atau dikenal dengan kapata-kapata.

Petuah bijak sang Ulama Maluku diantaranya Imam Rijali tampak dalam konten sajak religinya sebagai media interaksi sosial antar umat Bergama. Islam Maluku terkenal dengan pantong, nyanyian, cigulu-cigulu, kapatah tentang rasa, serta kearifan lokal lainnya yang diduga kuat bersumber dari akulturasi budaya lokal dengan Islam yang datang dari tanah Arab. Perjumpaan budaya inilah yang memberikan keunikan bagi Islam yang ada di negeri Raja-Raja ini.

\subsection{Kognitif etnoscience Orang Tulehu}

Etnoscience cognitive adalah pola pikir masyarakat negeri Tulehu dalam memproduksi pengetahuan. Sistem penyebaran pengetahuan terdiri dari patawali (sistem penyebaran informasi secara interpersonal dalam kelaurga yang digunakan dalam beberapa aspek yang dianggap penting oleh komunitas keluarga tertentu, masawere (sistem penyebaran pengetahuan untuk keluarga besar (Syarifudin, 2014), patanity (sistem komunikasi transendental mendoakan arwah leluhuhur yang telah mendahului mereka) (Kementerian Agama Republik Indonesia, 2013: 232). Masyarakat negeri Tulehu yang Kabupaten Maluku Tengah Provinsi Maluku memiliki level pemikiran dalam memproduksi pengetahuan terdiri beberapa benetuk antara lain adalah sebagai berikut; 1). Jahl (Jahilia) (level pengetahuan masyarakat yang memiliki pengetahuan science dan teknologi tapi tidak tau apa yang mereka lakukan. 2). Taqlid (level pengetahuan mempercayai pikiran orang tanpa ada daya kritis terhadap orang tua tersebut) (Azra, 2008:44), 3). Zhan (Kirakira/Prasangka), 4). Ma'rifah (level pengetahuan melihat, bukti objektif, menyaksikan realitas). Ajaran dasar yang membentuk pola pikir etnoscience masyarakat negeri Tulehu adalah proses reproduksi pengteahuan melalui komunikasi verbal dan non verbal, dalam paradigma pemikiran Yusuf Qardawi komunitasi ini dapat dikategorikan menggunakan penyebaran informasi dengan metode dakwah billisan (komunikasi verbal), dakwah bi al-Hal (komunikasi verbal dan non verbal).

\subsection{Etnoteknologi Desa adat di Tulehu}

Etnoteknologi etnis Negeri Tulehu lebih didominasi dengan tradisi tutur dalam sistem penyebaran Informasi. Hal ini disebabkan oleh sistem pengetahuan di Tulehu masih dikuasai oleh tradisi pengetahuan nenek moyang mereka. Misalnya tradisi etnoteknologi pasaware teknologi penyebaran informasi dengan cara tabaos titah negeri atau sistem transformasi pengetahuan dengan cara dari rumah ke rumah dan lorong-kelorong disebarkan ke public sesuai hasil rapat adat (Majid, 16 Mei 2016). Tradisi etnoscience dan etnoteknologi terdiri dari tiga sumber yakni dari sumber warisan dari nenek moyang, agama dari bahasa tutur dan media moderen, dan konstruksi budaya kolonial dalam memengaruhi tindakan etnoscience dan etnotechnology 
(Sciller, 2012: 112). Secara teknik wawasan etnoscience dan etnotechnology masyarakat lebih banyak didominasi oleh tradisi tutur sehingga setiap fakta ukurannya adalah level pengetahuan mempercayai pikiran orang tanpa ada daya kritis terhadap orang tua tersebut (taqlid) proses transformasi pengetahuan.

Rumatau yan gada di Tulehu sekitar 13 fam atau rumatau misalnya (Ohorellah, Umarellah, Lestaluhu, Nahumaruri, Tuasalamoni, Tehuatuella, Tehupelasuri, Nusanella, Tawainella, Pari, Sarlata, Lekasalaisa). Semua fam ini memiliki etnoscience dan etnotechnology dalam melakukan hubungan interaksi sosial adat dan antar adat. Etnotechnology terdiri dari tukang basar dari marga Tuasalamony tukang kacil itu dari marga Lestaluhu. Tuasalamony sebagai pengguna teknologi besar dan diberi amanah dalam melakukan proses transformasi pengetahuan di tengah publik. Jenis etnoscience dan etnoteknologi yang digunakan dalam proses transformasi pengetahuan:

1) Palaapa (Memanggil Orang); sistem penyebaran atau konstruksi sosial yang levelnya pada keluarga dengan menggunakan bahasa kekeluargaan dari rumah ke rumah, metode etnokomunikasi ini dilakukan pada acara-acara keluarga baca do'a, tahlil, dan ada orang yang mau masuk minta. Level etnokomunikasi termasuk orang-orang yang digunakan sebagai informan yang telah memiliki kredibilitas dalam keluarga.

2) Pasaware (Komunikasi religi) biasanya dilakukan di masjid untuk hari-hari besar agama Islam, dan ini juga dipakai untuk memanggil pela orang Tulehu. Pela Tulehu terdiri dari pela gandong, pela tolong-menolong.

3) Tabaos Titah; tabaos titas adalah konstruksi sosial dalam level pemerintahan adat yang dilakukan oleh struktur adat yang telah ditunjuk dalam rapat saniri negeri. Tabaos titah ini berfungsi sebagai media konstruksi sosial untuk publikasi pesan-pesan raja yang telah diputuskan dalam Baileo. Baileo adalah rumah adat sebagai tempat permusyawatan semua sistem sosial adat yang dipimpin langsung oleh raja dan diikuti oleh seluruh aparat negeri yang duduk dalam strktur adat.

4) Patanity; sistem doa yang dilakukan oleh tokoh adat bidang agama untuk melakukan tawassul kepada pada leluhur yang telah meninggal agar semua hajat itu dapat berjalan lancar. Akar kata dari Fatanity terdiri dari dua kata, pata, pati dan nity. Kata Fata atau pati dari kata Fattah (pemenang) sedangkan kata nity adalah niat harapan. Dengan demikian kata fatanity adalah adanya harapan yang kuat unutk memohon kepada Rabbul'alamin untuk dikabulkan segala permintaannya.

Menetapkan peraturan adat dan kewang di Negeri Tulehu dalam peraturan ini yang dimaksud dengan; Petuanan adalah wilayah kuasa (daratan dan lautan) dari negeri Tulehu. Kintal negeri adalah tanah-tanah tertentu yang dikuasai negeri Tulehu untuk diperuntukkan untuk kepentingan umum. Bangunan Negeri adalah bangunan-bangunan yang dibangun oleh pemerintah dan rakyat negeri Tulehu, karena itu menjadi milik pemerintah negeri dan rakyat Tulehu. Hurun Negeri adalah tanah-tanah tertentu yang dikuasai negeri Tulehu, terletak di atas negeri Tulehu diperuntukkan untuk kepentingan umum. Dusun Negeri adalah sebanyak 12 bidnag dusun yang dikuasai negeri Tulehu terletak didaratan rendah dalam wilayah negeri Tulehu dan berbatas dengan daerah capato badiri (daerah meulai menanjak) milik perorangan penduduk negeri Tulehu.

Ewang negeri adalah daerah kawasan hutan yang dikuasai Negeri Tulehu, teretak di daerah pegunungan daratan tinggi dalam wilayah kuasa negeri Tulehu. Pantai Negeri adalah daratan pantai yang dikuasai negeri Tulehu, terhitung mulai ombak pukul-pukul sampai batas air hitam putih serta tubir berserta segala potensi dan sumber alam yang dikandungnya seperti batu, batu karang, kerikil, pasir, ikan, hasil laut dan lainnya. Perairan negeri Tulehu adalah lajur laut sesudah batas hitam-putih aau tubir ke arah laut lepas, dimana nelayan tradisional Tulehu dan orang luar yang menangkap ikan dengan menggunakan peralatan seperti; sero, sero gantung, bagan dan alat pengakapan ikan lainnya. 
Sungai wailatu dan mareta adalah sungai-sungai yang dikuasai negeri Tulehu, yang mengalir dalam petuanan negeri Tulehu termasuk potensi dan sumber daya airnya digunakan untuk air minum, air mandi, air cuci, tempat membuang hajad(besar/kecil) dan lainnya. Sungai wairutung dan wai mamiang adalah sungai-sungai yang dikuasai negeri Tulehu, yang mengalir dalam petuanan negeri tulehu termasuk potensi dan sumber daya alam yang di kandungnya seperti batu, kerikil, ikan, udang, dan lain-lain. Sasi adalah larangan mengambil hasil-hasil didaratan dan atau dilautan dalam satu kurun tertentu. Orang luar adalah mereka yang bepergian lewat petuanan negeri Tulehu dan atau mereka yang sementara tinggal dalam petuanan negeri Tulehu tetapi bukan penduduk negeri Tulehu. Minuman keras adalah minuman yang sifatnya memabukkan seperti bier, anggur, sopi, dan lainnya. Perjudian adalah setiap permainan yang menggunakan uang dan atau benda lainnya sebagai taruhan. Belum dewasa adalah belum genap berusia 17 (tujuh belas) tahun di tulehu. Kepolisian adalah komando sektor kepolisian 1601-02 hitu timur di Tulehu.

Adat dan Kewang Tujuan dan Fungsi Tujuan adalah menjaga, memelihara, melindungi, dan mengayomi negeri Tulehu, harta miliknya serta segala kepentingannya, begitu juga dengan penduduk negeri Tulehu, harta miliknya dan segala kepentingannya. Fungsinya adalah menciptakan keamanan, ketentraman, ketertiban, dan kedamaian dalam masyarakat dan petuanan negeri Tulehu. Organisasi dan Tugas Organisasi kewang terdiri dari; kepala kewang, wakil kepala kewang, sekretaris kewang, wakil sekretaris kewang, bendahara kewang, wakil bendahara kewang, dan anak-anak kewang. Kepala kewang bertugas mengepalai kewang, menetapkan kebijaksanaan yang akan dijalankan oleh kewang, setelah mendapat perintah dari pemerintah negeri mana yang ahrus dengan persetujuan saniri negeri Tulehu.

Apabila kepala kewang berhalangan, maka wakil kepala kewang menjalankan tugas kepala kewang. Sekretaris kewang bertugas mengepalai pekerjaan administrasi kewang, melaksanakan pekerjaan tersebut baik atas perintah kepala kewang maupun inisiatif sendiri. Apabila sekretaris kewang berhalangan, maka wakil sekretaris kewang yang menjalankan tugas sekretaris kewang. Bendahara kewang bertugas mengepalai dan mengurus keuangan kewang, mencatat semua uang masuk keluar, membuat neraca dan dan segala kegiatan lainnya berhubungan dengan kegiatan kewang. Apabila Bendahara kewang berhalangan, maka wakil Bendahara kewang menjalankan tugas kepala kewang. Anak-anak kewang bertugas menjalankan dan melaksanakan perintah kepala kewang dengan penuh rasa tanggung jawab, jujur, kesatria, dan adil (Kare Steenbrink, 2000). Jumlah anak-anak kewang ditetapkan oleh pemerintah negeri Tulehu dengan persetujuan dari saniri negeri serta disesuaikan dengan kebutuhan. Personalia kewang ditetapkan oleh pemerintah negeri Tulehu dengan persetuajun dari saniri negeri Tulehu.

Kantor/Rumah, Rapat dan masa berlaku kewang, Seluruh kegiatan kewang dipusatkan pada kantor/rumah kewang Rapat kewang dilakukan sekurang-kurangnya sekali dalam sebulan. Untuk pertama kali, maka masa berlakunya kewang adalah dua tahun, terhitung mulai sejak kewang diangkat; Untuk seterusnya, maka masa berlakunya kewang adalah 1 (satu) tahun, terhitung sejak kewang diangkat. Kehidupan dan penghidupan dalam negeri tulehuSasi atas hasil-hasil di daratan dan lautan di umumkan oleh kewang: (a) melalui titah (tabaus titah), secara tertulis pada papanpapan pengumuman dan (c) dengan menggunakan tanda-tanda yang nyata; Barangsiapa melanggar ketentuan ini, dihukum oleh kewang dengan hukuman denda sebanyak banyaknya 10.000 bagi mereka yang mengambil kelapa, pala, bunga pala, cengkeh, daun atap, gaba-gaba, loleba, daun tikar, ikan, hasil laut lainnya.

\subsection{Perspektif Etnoscience dan Etnotechnology Dakwah}

Pengertian teknologi dakwah adalah segala sesuatu yang berkaitan dengan penggunaan alat bantu untuk memproses dan mentransfer data Al-Quran dan Sunnah dari mubalig ke mad'u atau dari perangkat yang satu ke lainnya. Oleh karena itu, teknologi dakwah, dengan teknologi informasi, dan teknologi komunikasi tidak terpisahkan dalam aplikasi dakwah. Jadi teknologi dakwah mengandung pengertian segala kegiatan yang terkait dengan pemrosesan, manipulasi, pengelolaan, pemindahan informasi agama Islam antar media. Istilah Teknologi Dakwah muncul 
setelah lahirnya disertasi ini sebagai satu cara pandang penggunaan teknologi digunakan dalam melakukan ibadah.

Perpaduan antara teknologi komputer (baik perangkat keras maupun perangkat lunak) dengan teknologi komunikasi dan teknologi dakwah satu perpaduan yang saling menunjang dan mengokohkan. Semangat teknologi dakwah pada capital spirtualnya, semangat teknologi informasi pada capital pengolahan data, dan semangat teknologi komunikasi pada pemaknaan simbol. Teknologi dakwah ini secara spesifik menelaah dan mengeksplorasi peran mubalig menggunakan teknologi dalam membahasakan dan mengkomunikasikan pesan-pesan Al-Quran dan Sunnah di tengah masyarakat.

Dari realitas ini dapat digambarkan bahwa ada beberapa hal yang menarik dalam proses komunikasi etnoteknologi komunikasi transcendental yang dikembangkan oleh masyarakat Tulehu yang tetap bertahan dengan warisan etnoteknologi komunikasi transendental sebagai alat untuk saling menyelamatkan, mendoakan, dan membahagiakan. Sistem ini berbeda dengan metode komunikasi yang diproduksi oleh ilmu modern dari aspek metode, fasilitas, dan Sumber daya manusia. Kalau teknologi media komunikasi modern lebih bersifat hedonis sedangkan system komunikasi etnoteknologi komunikasi transcendental lebih bersifat pentucian rohani, jiwa, batin, dan proses transformasi energy spiritual untuk kesehatan mental sebagai sasaran dari komunikasi etnoteknologi komunikasi transcendental.

\subsection{KESIMPULAN}

Semakin tinggi proses komunikasi etnoscience dan etnoteknologi dakwah dalam suatu masyarakat semakin rendah produksi sampah pemikiran dan sampah industry. Sehingga disimpulkan bahwa etnoscience dan etnoteknologi dakwah adalah media konstruksi sosial yang dapat memperbaiki peradaban multietnis dalam proses peningkatan kualitas kehidupan yang lebih humanis dengan memadukan secara etis etnoscience dan etnoteknologi dakwah dan produk teknologi modern sebagai Cakrawala baru dalam dunia ilmu pengetahuan.

\section{References}

Azyumardi Azra. (2008). Jaringan Ulama Timur Tengah dan Kepulauan Nusantara Abad XVII \& XVIII, Cet. II; Jakarta: Prenada Media.

S. Takdir Alisyahbana. (1992). Pemikiran Islam dalam Menghadapi Globalisasi Dan Masa Depan Umat Manusia Jakarta: Dian Rakyat.

C.A Adelman. (2015). Parallel Post-secondary Universe: The Certification System in Information Technology. Washington, D.C.: U.S. Department of Education,

Majid. (2016). Dampak revolusi industri terhadap perkembangan sosial, ekonomi dan demogfrafi di Maluku pada masa colonial di negeri Tulehi, wawancara Majid 16 Mei 2016.

John Naisbitt. (2002). High Tech High Touch (terj.). Jakarta: Pustaka Mizan, 2002.

Samad Umarella. (2016). Dosen IAIN Ambon Fakultas Tarbiyah Warga Desa Tulehu Kabupaten Maluku Tengah Provinsi Maluku wawancara di kantornya Senin, 2 Mei 2016.

Nur Tawainella, Dosen Universitas Darussalam Ambon dan Warga Desa Tulehu Kabupaten Maluku Tengah Provinsi Maluku wawancara di kantornya Senin, 23 Mei 2016.

Usman Thalib. (2012). Sejarah masuknya Islam di Maluku, (Cet. Kementerian Pariwisata dan Ekonomi Kreatif.

Nor Huda. (2013). Islam Nusantara: Sejarah Sosial Intelektual Islam Indonesia Cet. III; Yogyakarta: Ar-Ruzz Media.

Kementerian Agama Republik Indonesia. (2013). "Balai Penelitian dan Pengembangan Agama Makassar", Jurnal Al-Qalam, Volume 19 Nomor 2 November 2013. 
Syarifudin / UMRAN - International Journal of Islamic and Civilizational Studies. Vol.4, no.1-1, pp. 27 - 33

Kare Steenbrink. (2000). The Heavy Burden of the Religious Fragmentation and Geographical Isolation of the Moluccas.

Sciller. (2012). Imprealisme Culture Global, Cet. II; Sage Publishing.

Syarifudin. (2014). Peta Dakwah di Maluku Laporan Hasil penelitian tim Fakultas Dakwah dan Ushuluddin IAIN Ambon.

Saleh Lestaluhu. (2016). Warga Desa Tulehu Kabupaten Maluku Tengah Provinsi Maluku wawancara di kantornya Senin, 16 Mei 2016.

Peter L.Berger dan Thomas Luckman. (2013). Rekonstruction Reality, Sage Publishing.

Vannessa. (2012). Waste Electrical and Electronic Equipment (WEEE) Handbook, 1st Edition, Woodhead Publishing.

Warner and Feton. (1970). Proses Perubahan Etnoscience dan Etnotechnology, Cet. II. 